\title{
Efficacy of ramosetron in combination with polyethylene glycol of preparing for a colonoscopy
}

\author{
Min Kyu Kang, Byung Ik Jang, Jun Suk Park, Kyeong Ok Kim \\ Department of Internal Medicine, Yeungnam University College of Medicine, Daegu, Korea
}

Received: November 2, 2018

Revised: December 19, 2018

Accepted: December 24, 2018

Corresponding author:

Byung lk Jang

Division of Gastroenterology and

Hepatology, Department of Internal

Medicine, Yeungnam University

College of Medicine, 170,

Hyeonchung-ro, Nam-gu, Daegu

42415 , Korea

Tel: $+82-53-620-3831$

Fax: +82-53-623-8038

E-mail: jbi@med.yu.ac.kr
Background: Because of its efficacy and safety, polyethylene glycol (PEG) is generally used to prepare for colonoscopy. However, the side effects of PEG, including nausea, vomiting, abdominal discomfort, pain, and general weakness, tend to decrease patient compliance and satisfaction. The aim of this study is to investigate the efficacy and safety of PEG with $0.1 \mathrm{mg}$ ramosetron on colonoscopy patients who had difficulty taking PEG due to side effects or large volume.

Methods: From January to August in 2012, 28 patients who visited Yeungnam University hospital for a colonoscopy were prospectively enrolled. All enrolled patients were previous history underwent colonoscopy using PEG only in our hospital. The efficacy and safety of ramosetron were assessed through the use of a questionnaire, and compared previous bowel preparation.

Results: Compared to previous examination, the patients using the ramosetron reported less nausea, vomiting, abdominal discomfort, and abdominal pain, as well as a higher degree of compliance and satisfaction of the patient. There were no side effects reported with the use of ramosetron. However, overall bowel preparation quality was not better than the previous examination. Conclusion: In case of the use of ramosetron in combination with PEG for bowel preparation, patients experienced a higher rate of compliance and tolerance. Looking forward, ramosetron may become an option of pretreatment for bowel preparation.

Keywords: Bowel preparation; Colonoscopy; Polyethylene glycol; Ramosetron

\section{Introduction}

According to the increase of the proportions of colon disease year after year, the importance of colonoscopy examinations is growing. Besides, the general use of colonoscopies has been suggested for colon cancer screening. Thorough bowel preparation is necessary for the safe and accurate completion of the colonoscopy examination. Actually, diagnostic accuracy and therapeutic safety of the colonoscopy relies on the quality of the bowel preparation [1-5].

Though appropriate preparation is generally defined as one that allows the detection of colonic polyps $5 \mathrm{~mm}$ or larger [6], this definition does not consider the shape of the lesions, and it is well known that flat lesions are more difficult to detect. The cecal intubation rate and adenoma detection rate are two of the chief quality colonoscopic indices. Those have close relation with the quality of bowel preparation [7].

Inappropriate bowel cleaning can cause low detection rates of incipient and advanced adenomas, flat lesions, and flat adenomas [7-10]; it can also cause a higher rate of canceled procedures with increased costs, prolonged procedures, and a higher risk of complications [11].

Bowel preparation is one of the concerns that negatively affect the willingness of patients to receive the colonoscopy procedure 
$[12,13]$. Compliance to the preparation process is a main important factor for success colonoscopy, as compliance affects the quality of the bowel preparation. But, the preparation process has limitations due to side effects, and the low tolerance for the taste and the large amount of solution, which are the leading causes for avoiding the complete bowel preparation [14]. Polyethylene glycol (PEG) solution has been the favored bowel preparation agent to use prior to performing diagnostic and therapeutic colonoscopy procedures on the colon and rectum.

Ramosetron is a selective serotonergic 5-hydroxy-tryptamine (HT) receptor-3 antagonist that is used to prevent and treat postoperative or chemotherapy-induced nausea and vomiting $[15,16]$. The author supposes that ramosetron can improve a patient's tolerance and satisfaction regarding the PEG solution. However, the efficacy and tolerability of PEG with or without ramosetron has not been investigated. Based on that, we conducted a prospective, pilot study to evaluate the tolerability, and efficacy of ramosetron as an adjuvant in the PEG solution for colonoscopy preparation who had difficulty taking PEG due to side effects and large volume.

\section{Materials and methods}

\section{Patients}

Twenty-eight outpatients aged 17 to 80 years, scheduled for elective colonoscopy at Yeungnam University hospital from January to August 2012, were enrolled. All enrolled patients had experience with the bowel preparation process that is required for a colonoscopic examination in our hospital. The patients had negative willingness on previous colonoscopy due to difficulty drinking the PEG solution, regardless of degree of bowel preparation and PEG dosage. Patients were excluded if they had a megacolon, bowel obstruction, ileus, or other severe comorbidities that might prevent the colonoscopy from occurring. Patients were also excluded if they had colonoscopy for emergency purposes. The study was approved by the Institutional Review Committee of Yeungnam University hospital (YUH-12-015-M10).

\section{Methods}

PEG administration was started 12 hours before the colonoscopy examination. All patients were instructed to drink 4 liters of PEG solution if they had no side effects or difficulties. After starting to drink the PEG solution, patients were only allowed to have water. Ramosetron of $0.1 \mathrm{mg}$ (Nasea; Astellas, Tokyo, Japan) was administered one time, and it was given 1 hour before drinking the PEG solution.

Before receiving the current colonoscopy examination, patients filled out a questionnaire to estimate their acceptability and tolerability regarding the bowel preparation. In regards to tolerance, patients were evaluated using each quartile of the total amount PEG solution they drank. Patients were also questioned as to whether they experienced any side effects associated with the current bowel preparation such as nausea, vomiting, abdominal discomfort \& pain. They were also questioned about their satisfaction with the current bowel preparation. In the same enrolled patients, previous total amount PEG solution, side effects were also investigated in a written questionnaire before receiving the current colonoscopy. In other words, we divided the previous PEG only group and current PEG+ramosetron group in the same subject.

To estimate the efficacy of the bowel preparation, patients were evaluated using bowel preparation quality on the colonoscopic examination by experienced colonoscopist. Bowel preparation status was categorized into four groups as clear, fluid that can be sucked away, small amount of feces, and large amount of feces. Optimal bowel preparation status defined as the two groups including clear and fluid that can be sucked away. After the colonoscopy procedure, the colonoscopist filled out a questionnaire about the current bowel preparation status, compared the results of previous bowel preparation status, and calculated cecal intubation rate, withdrawal time, adenoma detection rate, and optimal bowel preparation status rate after reviewing colonoscopy images.

\section{Statistical analysis}

The primary endpoints of this study were the patients' tolerance and efficacy of the PEG-solution. Continuous variables were reported as mean \pm standard deviations and analyzed using independent t-tests. Results are expressed as counts and percentages as categorical data, and analyzed using Pearson's Chisquare test or Fisher's exact test, as appropriate. A $p$-value $<0.05$ was considered statistically significant.

\section{Results}

The baseline characteristics of current PEG+ramosetron group are presented in Table 1. The mean age of enrolled patients was $48.79 \pm 14.97$ years old. Male to female ratio was 1:1.54. Of the 28 patients, 11 patients had underlying diseases such as 5 diabetes mellitus (17.9\%), 6 hypertension (21.4\%), 5 cancer (17.9\%), 2 asthma (7.1\%), and 3 heart failure (10.7\%). Of the total patients, 13 patients $(46.4 \%)$ had a previous history of abdominal surgery. The mean previous colonoscopy interval time was $26.3 \pm 17.7$ months. The mean cecal intubation time and withdrawal time 
were $4.1 \pm 2.1$ and $6.7 \pm 2.4 \mathrm{~min}$, respectively.

Concerning the PEG volume, 12 of the 28 patients (42.9\%) were able to finish $100 \%$ ( $4 \mathrm{~L}$ ) of the PEG solution in the previous PEG only group. However 22 of the 28 patients (78.6\%) were able to finish $100 \%$ of the PEG solution in the PEG+ramosetron group $(p=0.019)$. The number of patients who finished less than half the amount of the PEG solution are 5 (17.8\%) and 1 (3.5\%) in previous PEG only group and PEG+ramosetron group, respectively. The patients' acceptability in these two groups was significantly different (Table 2).

With regard to side effects of the bowel preparation, several symptoms were assessed in the questionnaire, including nausea, vomiting, abdominal discomfort and abdominal pain. Side effects were more frequently found in the previous PEG only group than in the PEG+ramosetron group $(p<0.001)$. Of the total 28 patients, $18(64.3 \%)$ patients did not complain of any side effects in PEG+ramosetron group (Table 2).

The authors investigated the satisfaction of patients with the bowel preparation method. The proportion of excellent satisfaction in the PEG+ramosetron group (64.3\%) was higher than that in the previous PEG only group ( $64.3 \%$ vs. $19.7 \%, p<0.001$, respectively) (Table 2).
Table 1. Baseline characteristics of the PEG+ramosetron group

\begin{tabular}{lc} 
Characteristic & $\begin{array}{c}\text { PEG+ramosetron group } \\
(n=28)\end{array}$ \\
\hline Age (yr) & $48.8 \pm 14.9$ \\
Sex & $11(39.2)$ \\
$\quad$ Male & $17(60.7)$ \\
$\quad$ Female & $11(39.2)$ \\
Presence of comorbidities & \\
Comorbidities & $5(17.9)$ \\
$\quad$ Diabetes mellitus & $6(21.4)$ \\
$\quad$ Hypertension & $5(17.9)$ \\
$\quad$ Cancer & $2(7.1)$ \\
$\quad$ Asthma & $3(10.7)$ \\
Heart failure & $162.68 \pm 8.74$ \\
Height (cm) & $59.49 \pm 11.24$ \\
Weight (kg) & $21.77 \pm 3.44$ \\
BMl & $13(46.4)$ \\
History of abdominal operation & $26.3 \pm 17.7$ \\
Previous colonoscopy interval time (mon) & $4.1 \pm 2.1$ \\
Cecal intubation time (min) & $6.7 \pm 2.4$ \\
Withdrawal time (min) &
\end{tabular}

Values are presented as mean \pm standard deviation or number (\%), unless otherwise specified.

PEG, polyethylene glycol; BMI, body mass index.

Table 2. Comparison of the differences between previous PEG only group and PEG+ramosetron group at the same patients

\begin{tabular}{|c|c|c|c|}
\hline & Previous PEG only $(n=28)$ & PEG+ramosetron $(n=28)$ & $p$-value \\
\hline PEG taking dose (\%) & & & 0.019 \\
\hline 100 & $12(42.9)$ & $22(78.6)$ & \\
\hline 75 & $11(39.3)$ & $5(17.9)$ & \\
\hline 50 & $5(17.8)$ & $1(3.5)$ & \\
\hline Side effect & & & $<0.001$ \\
\hline Nausea/vomiting & $27(96.4)$ & $8(28.6)$ & \\
\hline Abdominal discomfort/pain & $1(3.6)$ & $2(7.2)$ & \\
\hline None & $0(0.0)$ & $18(64.3)$ & \\
\hline Patient satisfaction & & & $<0.001$ \\
\hline Excellent & $3(10.7)$ & 18 (64.3) & \\
\hline Average & $17(60.7)$ & $7(25)$ & \\
\hline Unsatisfactory & $8(28.6)$ & $3(10.7)$ & \\
\hline Bowel preparation & & & 0.175 \\
\hline Clear & $8(28.6)$ & $16(57.2)$ & \\
\hline Fluid that can be sucked away & $14(50.0)$ & $9(32.1)$ & \\
\hline Small amounts of feces & 4 (14.3) & $2(7.1)$ & \\
\hline Large amounts of feces & $2(7.1)$ & $1(3.6)$ & \\
\hline Optimal bowel preparation & $22(78.6)$ & 25 (89.3) & 0.052 \\
\hline \multicolumn{4}{|l|}{ Quality of colonoscopy } \\
\hline Cecal intubation rate & $27(96.4)$ & $27(96.4)$ & $p>0.999$ \\
\hline Adenoma detection rate & 8 (28.6) & 7 (25.0) & 0.118 \\
\hline
\end{tabular}

Values are presented as number (\%).

PEG, polyethylene glycol. 
The efficacy of the bowel preparation was categorized into four groups as clear, fluid that can be sucked away, small amount of feces and large amount of feces. As much as $78.6 \%$ of bowel preparation in the previous PEG only group was optimal and $89.3 \%$ of bowel preparation in PEG+ramosetron group was optimal $(p=0.052)$. Although not statistically significant, both groups showed a comparable overall assessment of bowel preparation $(p=0.175)$ (Table 2).

The cecal intubation rate and adenoma detection rate, which are quality indexes of colonoscopy quality, did not differ between the two groups. The cecal intubation rate accounted for $96.4 \%$ of both two groups, except for one patient with stenosis with Crohn's disease. Adenoma detection rate were $28.6 \%$ in previous PEG only group and $25.0 \%$ in the PEG +ramosetron group, which are not statistical significantly $(p=0.118)$.

\section{Discussion}

Bowel preparation before colonoscopy is usually considered as uncomfortable by patients. It is common for patients to complain that the bowel preparation is harder than the actual colonoscopy procedure. Accordingly, many kinds of agents have been studied in order to achieve comfortable and effective bowel preparation. Many reports about PEG solution have concluded that PEG is more effective and better tolerated than the combination of diet and laxative regimens, high-volume balanced electrolyte solutions, and mannitol-based solutions [17-20]. Even if PEG is usually well-tolerated, 5-15\% patients who take PEG do not complete the preparation because of the bad taste, large volume or side effects [21]. In particular, patients experiencing difficulty with PEG administration and side effects may have a negative willingness of colonoscopy, leading to poor compliance and avoidance of examination.

There are several studies that have evaluated the effects of prokinetics on bowel preparation. Abdullah et al. reported that the adjunct use of clebopride in PEG solution for bowel preparation tended to increase the acceptability, tolerability and efficacy [22]. Tajika et al. revealed that mosapride citrate can be an effective and safe adjunct to PEG solution which brings about improved bowel preparation status [23]. However, it has not been fully evaluated to add-on prokinetic agents with PEG in terms of the efficacy and safety of colonic cleansing. In addition, as the difficulty and side effects during PEG administration may increase the avoidance of colonoscopy, safer and more effective adjunctive agents are required.

Ramosetron (Nasea ${ }^{\oplus}$; Astellas), a new generation 5-HT3 antagonists developed newly in Japan, has a higher potency and longer lasting antiemetic effect than first-generation 5-HT3 antagonists $[24,25]$. Three-dimensional molecular modeling studies have revealed that ramosetron occupies the 5-HT binding site of 5-HT3 receptors with long lasting antagonism [26]. Ramosetron is commonly used to treat postoperative nausea and vomiting or chemotherapy-induced nausea and vomiting [27].

The present study showed that patient acceptability was superior in the PEG+ramosetron group compared to the previous PEG only group ( $p=0.019)$. With regard to side effects, ramosetron reduced the presence of nausea and vomiting $(p<0.001)$. In regard to patient satisfaction, the proportion of excellent satisfaction in the PEG+ramosetron group was higher than that in the previous PEG only group $(p<0.001)$. As to the efficacy of bowel preparation assessed by the colonoscopist, both groups showed comparable results $(p=0.175)$. This was consistent with results of other reports that showed no statistically significant differences between the regimens for bowel preparation [28-32].

Although good bowel preparations and PEG doses are known to be interrelated, no difference in bowel preparation status revealed between two groups. The reasons for this are as follows. First, the PEG dosage is measured in quarters, making it difficult to accurately dose PEG. That is, the difference in the amount of $1 \mathrm{~L}$ of PEG in each quartile may have affected the difference in the degree of bowel preparation. Second, differences in the dosing interval may have affected the bowel preparation. Non-compliance of dosing interval was not checked. Third, the previous PEG dose is likely to be inaccurate due to a colonoscopy interval of 2 years or more.

Generally, the PEG solution is very effective for bowel preparation before colonoscopy. But patients show a somewhat low tolerance due to the large amount of solution and the side effects that include nausea, vomiting and abdominal pain. In the present study, ramosetron could increase the tolerance and decrease various side effects. In addition, ramosetron may help to reduce negative willingness about colonoscopy by increasing the satisfaction of taking PEG.

There are some limitations in this study. First, although it is a prospective study, it is a small population-pilot study without a definite control group. No appropriate control group to compare with PEG+ramosetron group only was established. Second, recall bias can occur. As I aforementioned, depending on the memory, the data was collected in a form that filled the questionnaire with total amount of PEG solution and the side effects that occurred during the previous colonoscopy. Third, the effect of ramosetron can be overestimated. Fourth, due to the chart review format, accurate assessment of previous patients' characteristics and quality of colonoscopy including cecal intubation time and withdrawal 
time may be insufficient. Finally, grading of side effects is not evaluated, although no severe adverse effects were found to stop colonoscopy. However, this study was the first to compare efficacy with previous PEG alone group using PEG+ramosteron for bowel preparation in patients with difficult taking PEG.

In conclusion, similar to several prokinetics that were reported at previous study, ramosetron can be a good adjunctive agent for bowel preparation when used with PEG solution.

\section{Conflicts of interest}

No potential conflicts of interest relevant to this article was reported.

\section{ORCID}

Min Kyu Kang, https://orcid.org/0000-0002-1435-3312

Byung Ik Jang, https://orcid.org/0000-0002-3037-9272

Jun Suk Park, https://orcid.org/0000-0002-8193-7764

Kyeong Ok Kim, https://orcid.org/0000-0001-5799-7436

\section{References}

1. Regula J, Rupinski M, Kraszewska E, Polkowski M, Pachlewski J, Orlowska J, et al. Colonoscopy in colorectal-cancer screening for detection of advanced neoplasia. N Engl J Med 2006;355:186372.

2. Piscatelli N, Hyman N, Osler T. Localizing colorectal cancer by colonoscopy. Arch Surg 2005; 140:932-5.

3. Sonnenberg A, Delcò F. Cost-effectiveness of a single colonoscopy in screening for colorectal cancer. Arch Intern Med 2002;162:163-8.

4. Heitman SJ, Manns BJ, Hilsden RJ, Fong A, Dean S, Romagnuolo J. Cost-effectiveness of computerized tomographic colonography versus colonoscopy for colorectal cancer screening. CMAJ 2005;173:877-81.

5. Wexner SD, Beck DE, Baron TH, Fanelli RD, Hyman N, Shen $\mathrm{B}$, et al. A consensus document on bowel preparation before colonoscopy: prepared by a task force from the American Society of Colon and Rectal Surgeons (ASCRS), the American Society for Gastrointestinal Endoscopy (ASGE), and the Society of American Gastrointestinal and Endoscopic Surgeons (SAGES). Gastrointest Endosc 2006;63:894-909.

6. Rex DK, Bond JH, Winawer S, Levin TR, Burt RW, Johnson DA, et al. Quality in the technical performance of colonoscopy and the continuous quality improvement process for colonoscopy: recommendations of the U.S. Multi-Society Task Force on
Colorectal Cancer. Am J Gastroenterol 2002;97:1296-308.

7. Harewood GC, Sharma VK, de Garmo P. Impact of colonoscopy preparation quality on detection of suspected colonic neoplasia. Gastrointest Endosc 2003;58:76-9.

8. Chokshi RV, Hovis CE, Hollander T, Early DS, Wang JS. Prevalence of missed adenomas in patients with inadequate bowel preparation on screening colonoscopy. Gastrointest Endosc 2012;75:1197-203.

9. Parra-Blanco A, Nicolas-Perez D, Gimeno-Garcia A, Grosso B, Jimenez A, Ortega J, et al. The timing of bowel preparation before colonoscopy determines the quality of cleansing, and is a significant factor contributing to the detection of flat lesions: a randomized study. World J Gastroenterol 2006;12:6161-6.

10. Chiu HM, Lin JT, Lee YC, Liang JT, Shun CT, Wang HP, et al. Different bowel preparation schedule leads to different diagnostic yield of proximal and nonpolypoid colorectal neoplasm at screening colonoscopy in average-risk population. Dis Colon Rectum 2011;54:1570-7.

11. Sharara AI, Abou Mrad RR. The modern bowel preparation in colonoscopy. Gastroenterol Clin North Am 2013;42:577-98.

12. Jones RM, Devers KJ, Kuzel AJ, Woolf SH. Patient-reported barriers to colorectal cancer screening: a mixed-methods analysis. Am J Prev Med 2010;38:508-16.

13. Jover R, Zapater P, Polanía E, Bujanda L, Lanas A, Hermo JA, et al. Modifiable endoscopic factors that influence the adenoma detection rate in colorectal cancer screening colonoscopies. Gastrointest Endosc 2013;77:381-9.

14. Burke CA, Church JM. Enhancing the quality of colonoscopy: the importance of bowel purgatives. Gastrointest Endosc 2007;66:565-73.

15. ASHP therapeutic guidelines on the pharmacologic management of nausea and vomiting in adult and pediatric patients receiving chemotherapy or radiation therapy or undergoing surgery. Am J Health Syst Pharm 1999;56:729-64.

16. Gan TJ, Diemunsch P, Habib AS, Kovac A, Kranke P, Meyer TA, et al. Consensus guidelines for the management of postoperative nausea and vomiting. Anesth Analg 2014;118:85-113.

17. Chan CH, Diner WC, Fontenot E, Davidson BD. Randomized single-blind clinical trial of a rapid colonic lavage solution (Golytely) vs. standard preparation for barium enema and colonoscopy. Gastrointest Radiol 1985;10:378-82.

18. Burke DA, Manning AP, Murphy L, Axon AT. Oral bowel lavage preparation for colonoscopy. Postgrad Med J 1988;64:772-4.

19. Adler M, Quenon M, Even-Adin D, Jeanmart J, Van Gossum A, Bourgeois N, et al. Whole gut lavage for colonoscopy- 
-a comparison between two solutions. Gastrointest Endosc 1984;30:65-7.

20. Beck DE, Fazio VW, Jagelman DG. Comparison of oral lavage methods for preoperative colonic cleansing. Dis Colon Rectum 1986;29:699-703.

21. Marshall JB, Pineda JJ, Barthel JS, King PD. Prospective, randomized trial comparing sodium phosphate solution with polyethylene glycol-electrolyte lavage for colonoscopy preparation. Gastrointest Endosc 1993;39:631-4.

22. Abdullah M, Rani AA, Fauzi A, Syam AF, Makmun D, Simadibrata $\mathrm{M}$, et al. A randomized, controlled, double-blind trial of the adjunct use of Clebopride in polyethylene glycol electrolyte (PEG) solution for colonoscopy preparation. Acta Med Indones 2010;42:27-30.

23. Tajika M, Niwa Y, Bhatia V, Kawai H, Kondo S, Sawaki A, et al. Efficacy of mosapride citrate with polyethylene glycol solution for colonoscopy preparation. World J Gastroenterol 2012;18:2517-25.

24. Rabasseda X. Ramosetron, a 5-HT3 receptor antagonist for the control of nausea and vomiting. Drugs Today (Barc) 2002;38:75-89.

25. Kim WO, Koo BN, Kim YK, Kil HK. Ramosetron for the prevention of postoperative nausea and vomiting (PONV): a meta-analysis. Korean J Anesthesiol 2011;61:405-12.

26. Ohta M, Suzuki T, Furuya T, Kurihara H, Tokunaga T, Miyata K, et al. Novel 5-hydroxytryptamine (5-HT3) receptor antagonists. III. Pharmacological evaluations and molecular modeling studies of optically active 4,5,6,7-tetrahydro$1 \mathrm{H}$-benzimidazole derivatives. Chem Pharm Bull (Tokyo) 1996;44:1707-16.

27. Kim KR, Kang G, Ki MS, Shim HJ, Hwang JE, Bae WK, et al. A randomized, double-blind pilot study of dose comparison of ramosetron to prevent chemotherapy-induced nausea and vomiting. Biomed Res Int 2015;2015:523601.

28. Rostom A, Jolicoeur E, Dubé C, Grégoire S, Patel D, Saloojee $\mathrm{N}$, et al. A randomized prospective trial comparing different regimens of oral sodium phosphate and polyethylene glycolbased lavage solution in the preparation of patients for colonoscopy. Gastrointest Endosc 2006;64:544-52.

29. Brady CE 3rd, DiPalma JA, Pierson WP. Golytely lavage--is metoclopramide necessary? Am J Gastroenterol 1985;80:180 4.

30. Rhodes JB, Engstrom J, Stone KF. Metoclopramide reduces the distress associated with colon cleansing by an oral electrolyte overload. Gastrointest Endosc 1978;24:162-3.

31. Froehlich F, Fried M, Schnegg JF, Gonvers JJ. Low sodium solution for colonic cleansing: a double-blind, controlled, randomized prospective study. Gastrointest Endosc 1992;38:579-81.

32. Huppertz-Hauss G, Bretthauer M, Sauar J, Paulsen J, Kjellevold $\varnothing$, Majak B, et al. Polyethylene glycol versus sodium phosphate in bowel cleansing for colonoscopy: a randomized trial. Endoscopy 2005;37:537-41. 